JUSTYNA JANIK

Faculty of Management and Social Communication Jagiellonian University in Kraków, Poland

\title{
The material world of digital fictions ${ }^{\star}$
}

\begin{abstract}
Aвstract. Janik Justyna, The material world of digital fictions. "Images” vol. XXIX, no. 38. Poznań 2021. Adam Mickiewicz University Press. Pp. 57-72. ISSN 1731-450X. DOI 10.14746/i.2021.38.04.

This paper explores the interdependency between digital matter and the representational or mimetic layer of the digital game object. The main aim is to foreground the mechanisms by which the representational elements of the game world emerge from the materiality of the process of play. These mechanisms are examined from the perspective of the ontology of the game object. The issue of digital materiality will be linked with the aesthetical explorations of Tadeusz Kantor, who emphasised the relation between the materiality of the theatre and its fictional elements. As the main example of this analysis, I will focus on Undertale (Toby Fox, 2015) as an example of a game that plays with the boundaries between the fictional world being presented and the elements of digital materiality that are usually hidden from the player's sight.
\end{abstract}

KEYwORDs: digital materiality, Tadeusz Kantor, fiction, Undertale

Cyberpunk 2077 (CD Projekt, 2020) was unquestionably one of the most eagerly awaited digital games of 2020. The vast open world of the dystopian Night City, ready to be freely explored, should, in theory, have impressed players. However, this world, as well as the stories within it, become almost invisible in most of the community's reactions and comments. Many first impression accounts instead pointed to the broken digital materiality of the game. Cyberpunk 2077's environment was filled with glitches that not only made the game look ridiculous, but also, in some cases, rendered it unplayable, with the game software crashing or blocking progress in some quests.

Quite apart from the well-documented issues regarding the corporate systems of production in the game development industry, the game's problematic launch also highlights a more conceptual point: namely, the fact that the game story and world design cannot shine on their own, but are supported by the digital materiality of the game object. Accordingly, in this paper, I will focus on this interdependency between the digital matter and the representational, or mimetic, layer of the digital game object. The 'digital game object' here is understood not as a specific in-game object - a thing that the player can encounter and interact with inside the virtual environment - but as referring to the digital game software as a whole digital artefact, connected to both the gaming hardware and the body of the player. It is, as Olli Tapio Leino

* The article was created within the research project PRELUDIUM 14 financed by National Science Centre, Poland (Jagiellonian University 2017/27/N/ HS2/00672, "Gra jako obiekt oporny. Relacja gracza
Images

vol. XXIX/no. 38

Poznań 2021

ISSN 1731-450X 
suggests, a playable artefact, in which the materiality and the process of play are intertwined together. They cannot be separated, as is the case with other kinds of games, like, for example, board games. While, during a game of Monopoly, the player needs to internalise the rules in order to give meaning to the plastic and cardboard materials in the box and thereby enact the process of play, during a digital gameplay session, they are thrown into the gameplay situation, where they can act only within the premises of the gaming software, its digital materiality and the processes that run it.[1] Therefore, the digital game object can be perceived as a complex actant that bonds with the player in the process of play, which can be understood as a mechanism of communication.

The main aim of this paper is to foreground these mechanisms of communication by exploring the way that the representational elements of the game world emerge from the materiality of the process of play. This will not, however, be done from the perspective of poetics, but with a focus on the ontology of the game object. The digital game object, as a complex cultural and technological artefact, needs to be approached from a perspective that reflects that complex nature. Therefore, in my analysis, I will combine the work of Yuk Hui and Matthew G. Kirschenbaum to explore the issue of digital materiality, which I understand as an uninterrupted process of becoming of interconnected beings, which is not based on the substance they are made of. As for the question of fiction, I will follow the aesthetical exploration of Tadeusz Kantor, who, in his work, emphasised the relation between the materiality of the theatre and the illusion that is created by the text of the play. To combine those approaches with the question of in-game communication, I will use Tomasz Majkowski's exploration of the complexity of the multimodal nature of digital game language. This will make the argument that we can productively draw parallels between Kantor's theatrical ontology and the ontological situation that happens in digital games. As a main example of this analysis, I will focus on Undertale (Toby Fox, 2015), which is a game that plays with the boundaries between the fictional world being presented and the digital materiality elements which are usually hidden from the player's sight.

The digital materiality of the game object
The idea of the digital game object seems to be premised on a dualistic understanding of its ontological status. On the one hand, it is treated as an object that we can buy and later install on our gaming equipment. The world 'play' points, however, to the fact that the game is also a process; by 'process' here, we can refer both to the process of play, as well as the algorithmic processes running in the game software. As I have mentioned above, the digital game is, after all, an artefact that is playable. But how can something that does not seem to be a physical object be ontologically involved with the phenomenon of materiality?
[1] O.T. Leino, Death loop as a feature, "Game Studies: The international journal of computer game research"
2012, vol. 12, no. 2, <http://gamestudies.org/1202/articles/death_loop_as_a_feature $>$, accessed: 21.01.2021. 
We can start approaching this question by recognizing an internal division that clearly suggests that the digital game object is a structure built from many different elements. Most well-known existing definitions of 'game', like Jesper Juul's[2] and Katie Salen and Eric Zimmerman's, [3] (in)directly point out to this phenomenon by describing a game as a system. For Alexander Galloway, who is more interested in the mediality of digital games, the gaming system consists of three main components: the gaming software, the machine (or computer hardware) and the player.[4] All three are connected through the action of play.

From Galloway's argument, two important premises can be extracted: that the gaming system contains both human and non-human elements that are equally important for the experience of play, and that each of these elements are already, on their own, complex beings. The game software could, for a start, be broken down into code, mechanics and aesthetic layers. Hardware, too, consists of many elements, from microprocessors to plastic cases. The player's body, on the other hand, is not only a biological body, but also a mental and socio-cultural construct. All of those bodies exist not only on the micro level of player's involvement in the gaming situation, but also on the macro level, outside the game space, in more day-to-day situations. [5]

The experience of play is deeply anchored inside the materiality of these three bodies, and the special relationship that connects them. To explain this, I would like to start with the body of the hardware. Here, the idea of materiality seems quite straightforward. The gaming hardware is, after all, something we can touch: a screen, a processor, a graphics card, a controller. The hardware being used to play a game can significantly influence the experience of play. This was visible in the case of Cyberpunk 2077, as the version that was available for eighth-generation consoles, namely the Playstation 4 and Xbox One, suffered from numerous performance issues, and the impressions of players who played the game on these platforms were significantly different from those who played the game on high-end PCs or ninth-generation consoles like the Playstation 5 or Xbox Series S/X.

The hardware we use not only shapes what we see on screen, but also how we feel it. It allows for the act of communication with the virtual world. Rune Klevjer, using the phenomenological perspective of Maurice Merleau-Ponty, points out that gaming hardware is a means that allows the player's body to extend through the body of the avatar right into the digital environment. In the moment of digital game play, the player gains the possibility to operate in a different space that has different qualities. Despite those differences, the feeling of tactile con-

[2] J. Juul, The game, the player, the world: looking for a heart of gameness, [in:] Level Up: Digital games research conference proceedings, ed. M. Copier, J. Raessens, Utrecht 2003, pp. 30-45.

[3] K. Salen, E. Zimmerman, Rules of Play. Game design fundamentals, Cambridge 2004, p. 80.
[4] A.R. Galloway, Gaming: Essays on algorithmic culture, Minneapolis 2006, p. 2.

[5] G. Calleja, In-Game: From immersion to incorporation, Cambridge 2011, pp. 38-42. 
tact with the game is being created.[6] To illustrate this, we can think of any control mechanism in a game that simulates a real action. In Firewatch (Campo Santo, 2016), for example, pressing and releasing the trigger button on our controller when we want to choose a dialogue option mimics the way that we operate a walkie-talkie.

This tactile feeling does not have to be connected only to actions that we can take in the game environment, but also to the audiovisual aspect of the game. This is the case in games such as Rez (United Game Artists, 2001) or Tetris Effect (Monstars Inc. \& Resonair, 2018), where the hypnotic images filled with pulsating music swallow the player and their body, at the same time as they are consumed by the player.

Moreover, as Tom Apperley suggests, the physical context of play - where we are playing and with whom - is as important as our gaming equipment. For him, the gameplay phenomenon is deeply rooted inside the materiality of everyday activities. He argues that, by following Henri Lefebvre's idea of rhythmanalysis, as well as the concept of media ecology as proposed by Matthew Fuller, we can see how the materiality of the hardware is by default connected with the body of the player, and how both of them are also being shaped by the context of play: "Bodies are where everyday life interfaces with the game screen; it is through the body that the gaming technology is experienced, and the body is the site where these diverse fields are contextualized and interact." [7]

Just as we modify or upgrade our gaming equipment to give us new experiences, the hardware and the context of play also change us and our bodies. We adjust not only our playing strategies - we will play the same game differently in a gaming pub with our friends and alone on the couch in our living room during an online tournament - but also our bodies, in a quite literal fashion.[8] For example, the more we play games that demand dexterity, the more we improve our eye-hand coordination. In a more negative sense, repetitive strain injury (RSI) can develop while holding and operating game controllers for extended periods of time.

All of the aforementioned examples emphasise what Apperley strongly suggests; namely, that the process of play is deeply embedded in embodied materiality and the surrounding social context. Moreover, we cannot talk about bodies of play without taking into consideration the digital body of the game object, which is an integral part of this material connection. In this context, the notion of materiality is not restricted only to beings that are physical in nature. Any kind of digital data, including digital games, can be analysed in the context of materiality. They not only leave traces when deleted from the hardware, but also carry a mark of the changes that were inflicted

[6] R. Klevjer, Enter the Avatar. The phenomenology of prosthetic telepresence in computer games, [in:] The Philosophy of Computer Games, eds. J.R. Sageng, F. Hallvard, L.M. Tarjei, Dordrecht 2012, pp. 24-26.
[7] T. Apperley, Gaming Rhythms: Play and counterplay from the situated to the global, Amsterdam 2010, p. 20.

[8] Ibidem, pp. 36-37. 
upon them during the meeting with other beings; for example, the pieces of code that are no longer functional after updating the software with a newer version, which are left behind in the final version of the game. Matthew G. Kirschenbaum calls this type of materiality "forensic materiality." [9] Alongside forensic materiality, we can also understand the game object in terms of its "formal materiality." [10] This is more abstract in nature, referring to the ways in which data sets are shaped by the organizing schemata within which they are positioned.[11] In both cases, we see how strongly physical matter is intertwined with process. However, as Yuk Hui argues, the materiality of the digital object does not have to rely on the matter of substance. Digital objects have no substance; instead, "data [...] becomes the new material medium of operation," [12] which emphasises that materiality has relational character.

For Hui, digital objects are composed of data that can be collected, stored, transmitted, or rearranged.[13] Thanks to the process of the materialization of causalities, these data sets can bond together in the form of a digital object. Later, this digital object - like, for example, a photograph -is positioned within a certain structure or regime, and, as a result, is shaped in a specific way. In other words, it is placed in a certain set of relationships that further shape it.[14] The same picture will look different - and, as an object, will behave differently and grant us different affordances - if we open the file in a photo-editing app than if we upload it to a social media platform. Each system follows its internal logic, which gives the digital object inside it a specific, concrete shape. After being uploaded on a social media platform, the picture enters into relationships with the other photos on the platform, and the algorithms that determine who the photo will be seen by, how it will be displayed, and so on. It becomes, in other words, a specific object in its specific context, and, if we change the context, we will change the object itself.[15] As digital objects, games tend to be far more complex than a digital photo, but we can assume that they are based on a similar principle, as, they are both sets of data subordinated to a specific structure that is based on causal processes.

With this approach, it is not only the organic body of the human player and the non-organic body of the hardware that can be analysed in the context of the materiality of play, but also the digital body of the game. Even if game studies does make mention of the materiality of the game object (as, for example, in the case of Leino, quoted above), the question of what this materiality really is is rarely answered. Looking at

[9] M.G. Kirschenbaum, Mechanisms: New media and the forensic imagination, Cambridge, MA, - London 2012, pp. 9-13.

[10] Ibidem, p. 9.

[11] Ibidem, pp. 11-15.

[12] Y. Hui, Towards a relational materialism, "Digital Culture \& Society" 2015, vol. 1, no. 1, p. 140.
[13] Idem, What is a digital object?, "Metaphilosophy" 2012, vol. 4, no. 43, p. 388.

[14] B.d., Interview with Yuk Hui in "Popphilosophy", February 24, 2017, <http://philochina.org/?p=231>, accessed: 21.01.2021.

[15] See: Y. Hui. Towards A Relational Materialisms..., pp. 117-119; idem, What is a Digital Object?..., p. 389. 
this problem from the perspective of Hui's philosophy, we can decouple the notion of the materiality of digital artefacts from the physicality of the technology. The game is no longer something chained to a specific hardware configuration. It is an ever-changing digital object that is being actualised through its specific relationships, and its materiality will depend on the specific data structures constituting it, evolving and changing as it is shaped, for example, in its relationship to the developing console software or update patches.

This relational nature of digital materiality also highlights the other side of the ontological duality of the digital game object: the process. We can talk about processuality in two ways here: firstly, in terms of the algorithmic processes of the game software, and, secondly, in terms of the processual character of the performance of play. In the first case, especially when we perceive the game object as a playable artefact, as Leino suggests, the materiality of the digital game is intertwined with its processes, and we cannot separate the two. This connection has a power over the player, because it imposes the gameplay condition on them. We are bound to the way the game object allows us to act and progress, given that it has the "ability to evaluate the user's choices and open up or delimit freedom of choice accordingly." [16] During the moment of digital gameplay, we need to behave according to what the gaming software requires of us.

In the same way, Veli-Matti Karhulahti points out that the main ability of the game is that of evaluating performances, which, in a way, combines both the performance aspect of play and the processual nature of the digital game object. The player and their actions are constantly being evaluated by the game, depending on the criteria adopted by the evaluator, which could be both the game as well as the player.[17] This emphasises the fact that the relationship between the bodies of play has a performative character that also constructs their own materiality. What is interesting in this context is that the processual character of play, moreover, is responsible for its potential for generating new meanings during the gameplay connection. As Thomas Malaby points out, "Each game is an ongoing process. As it is played it always contains the potential for generating new practices and new meanings, possibly refiguring the game itself,' [18] which indicates that the relational materiality of the game object is a potential source of the narrative content of the game, beyond just the level of representation. On the basis of this insight, in the next section, I will move on to considering how fiction can directly emerge through the performativity of the material bodies involved in the processes of digital gameplay.

[16] O.T. Leino, op.cit.

[17] V.-M. Karhulahti, Defining the videogame, "Game Studies. The international journal of computer game research" 2015, 2(15). Retrived from <http://gamestudies.org/1502/articles/karhulahti>, accessed: 21.01.2021.
[18] T. Malaby, Beyond play: A new approach to games, "Games \& Culture" 2007, vol. 1, no. 2, p. 8. 
To better explore this topic of the dependence between the materiality of the game object and the performative processes that can Fiction in Kantor's transform the bodies of play, I will use the aesthetic explorations of Tadeusz Kantor. In my previous work, I have already explored the relevance of Kantor's thought for considering the connections defining the situation of digital game play.[19] There, I focused on Kantor's concept of the bio-object,[20] repurposing it to explain how the relationship between the player and the game object influences the shape of each of the involved actants, as well as producing a meaning-generative tension between the two. This tension is created during the process of play, when the human and non-human elements are caught in a struggle to gain a dominant position. The struggle is constant - sometimes we beat a game, sometimes a level is just too difficult to overcome - but it creates the opportunity to produce new meanings. This new meaning could be a new strategy or a funny glitch, but it could also be fiction.

Kantor mentions in his essay that:

The FICTION (plot) of a drama, continuously disappearing and reappearing, "shone through" the "life" of these bi o- object s. [...]

Equally significant is this characteristic of the disappearance and reappearance of a dramatic plot, FICTION. At times, it suddenly disappeared inexplicably; at times, it appeared unexpectedly.[21]

This indicates that, during the performative and dominative struggle between bodies of play, there is a possibility for story to emerge. Kantor's theoretical writing, then, can serve as a lens through which to examine how the fictional elements of a game appear through the materiality of play. This approach varies from the perspectives on fiction that have been presented in the field of game studies in, for instance, the work of Espen Aarseth,[22] Nele Van de Mosselaer,[23] and Jon Robson and Aaron Meskin.[24] Such existing perspectives have tended to focus mostly on the relation between different elements inside the game environment and the question of representation, not looking at the game object as a whole body of play. Other approaches grounded

[19] J. Janik, Glitched perception: beyond the transparency and visibility of the video game object, "TransMissions: Journal of Film and Media Studies" 2017, vol. 2, no. $2,<$ http://transmissions.edu.pl/glitched-perception-beyond-the-transparency-and-visibility-of-the-video-game-object/>, accessed: 21.01.2021, eadem, Ghosts of the present past: Spectrality in the video game object, "Journal of the Philosophy of Games" 2019, vol. 1, no. 2, <https://journals.uio.no/ JPG/article/view/2943>, accessed: 21.01.2021.

[20] T. Kantor, Teatr śmierci: Teksty z lat 1975-1984, Wrocław 2004, pp. 397-415.

[21] T. Kantor, The Room: Maybe a New Phase (1980), [in:] M. Kobialka, Further On, Nothing: Tadeusz Kantor's Theatre, Minneapolis 2009, p. 359.
[22] E. Aarseth, Doors and perception: fiction vs. simulation in games, "Intermédialités / Intermediality" 2007, no. 9, p. 35-44, <https://doi. org/10.7202/1005528ar $>$, accessed: 21.01.2021. [23] N. Van de Mosselaer, Fictionally flipping tetrominoes? Defining the fictionality of a videogame player's actions, "Journal of the Philosophy of Games" 2018, vol. 1, no. 1, <https://doi.org/10.5617/jpg.6035>, accessed: 21.01.2021.

[24] J. Robson \& A. Meskin., Video games as self-involving interactive fictions, "The Journal of Aesthetics and Art Criticism" 2016, vol. 74, pp. 165-177, <https:// doi.org/10.1111/jaac.12269>, accessed: 21.01.2021. 
in narratology, like that of Marie-Laure Ryan,[25] generally make the case that you can fully immerse yourself into the fictional world only if you stop paying attention to the material side of the narrative artefact. A similar approach is also represented by Krzysztof M. Maj,[26] with his focus on world-building processes.

To understand the phenomenon of fiction in Kantor's art, and how it can be used in the context of digital games, we need to focus on two concepts that endure in his theatre over the years: reality and illusion.[27] Kantor's approach to art evolved a great deal during his active years, but, even if they took different manifestations, the linked ideas of reality and illusion marked all the different periods of Kantor's explorations, from his beginnings in underground theatre in occupied Kraków during World War II, until his final performances with the group Cricot 2 (Theatre of (Love and) Death period).

Krzysztof Pleśniarowicz describes this underlying theatrical ontology as "a constant pulsation between escaping from the falsifying truth of illusion [...] and striving to regain the irrevocably lost connection between man and reality [...]." [28] 'Illusion' here is quite a vague term, and often in Kantor's writings, it appears to be interchangeable with the concept of fiction.[29] Sometimes, it is directly connected to the dramatic text of the play. In other cases, it refers to the representation of anything that is not a part of the materiality of the theatre, that suggests there is something beyond what is seen.

For a long time in his artistic career, Kantor was strongly opposed to this concept, and perceived fictional elements in the theatre as something that blocked performative art from elevating its status above being just a medium for the dramatic text, and for creating the illusion of a different reality. Instead, Kantor intended to explore the notion of reality or realness, making the theatrical performance into the presentation of something that is devoid of signifié.[30]

For Kantor, this demanded an approach that was rooted in the materiality of the theatre, which consisted of objects, the bodies of the actors and their actions, a blurred division between audience and stage, as well as the audience's active participation in creating the play.[31] Objects in his theatre had a special status, and were never treated as a simple part of the scenography. They were often ready-made, found in garbage sites, deprived of human functionality. Because they did not represent anything besides their own existence, Kantor called these objects "poor".[32]

With time, this physical matter of the spectacle started to be insufficient to express reality as Kantor wanted to. With the arrival of

[25] M-L. Ryan, Avatars of Story, Minneapolis 2006. [26] K.M. Maj, Światotwórstwo w fantastyce. Od przedstawienia do zamieszkiwania, Kraków 2019. [27] J. Kłossowicz, Tadeusz Kantor - teatr, Warszawa 1991, p. 76.

[28] K. Pleśniarowicz, Teatr Śmierci Tadeusza Kantora, Chotomów 1990, p. 22.
[29] Por. K. Święcicki, Historia w teatrze Tadeusza Kantora, Poznań 2007, pp. 219-222.

[30] K. Pleśniarowicz, op.cit., p. 23.

[31] Ibidem, pp. 22-23.

[32] T. Kantor, op.cit., p. 461. 
the final part of his work, in the Theatre of (Love and) Death period, he turned to the notion of memory. This was acted out through the movement of the actors on stage, carrying with it the potential to generate an interpretative shock that would keep the audience in a constant state of attention/surprise. [33]

In this period of his theatre, 'fiction' in the sense of a story originating in a dramatic script was replaced by the symbolism of memories, which became part of the new reality.[34] Over time, then, Kantor came to accept reality and illusion as elements that need each other, even if they are in a state of a constant struggle with each other. This was a logical evolution of his art, especially considering that he treated the dramatic texts he used in his spectacles as ready-made objects. $\mathrm{He}$ engaged with them on a deeper level, deconstructing them as he did with Witkacy's dramas, rather than simply making an adaptation.[35] Fiction was always an element that emerged on stage from the actions between the different bodies - the human body of the actor and the non-human bodies of the theatrical objects - that were connected to each other through the process of play, a process which, as Kłossowicz notes, is situated between reality and illusion. It does not serve to recreate something, but rather to build connections between different elements of the performance, connections within which there is always room for chance and change.[36]

But how can this situation translate in the context of digital gameplay? It seems to be completely different at face value. Most game designers and players want the materiality of the game to be hidden to some degree. This is particularly the case in triple-A games that are focused on conveying a specific story, creating the illusion - in Kantor's understanding of this word - of a coherent, vivid, represented world, where the digital aspect of its existence are hidden from the player's eyes. Even if the game is not story-based, the mimetic dimension is still prominent, for example, as a part of the simulation/translation of the action into the digital void. We do not care about the story in Fortnite (Epic Games, 2017), for example, but we do care about how the weapons work and how we can execute the best kill. The materiality of the game object, as well as the processes that are running them, are still hidden. However, thanks to the way it communicates with players, the materiality of the game is inescapable.

The mechanism of how the digital game communicates is as complex as the digital artefact itself. When we talk about the creation of meaning during a playthrough, we need to focus not only on the visual and auditory signals that we receive, but also on how, and by what actions, they are conveyed. Tomasz Majkowski points out that the story layer of the game is an integral part of the mul-

[33] K. Pleśniarowicz, op.cit., p. 23.

[34] T. Kantor, op.cit., p. 406.
[35] K. Święcicki, op.cit., pp. 218-220.

[36] J. Kłossowicz, op.cit, pp. 56-57.
Material performances of digital fictions 
timodal language by which the game communicates its senses.[37] The story layer, however, is strictly connected with other layers of the game; namely, gameplay, space and rules. The layers intersect and interact with each other to create the game experience of heavily narrative-based games.

While Majkowski uses the Bakhtinian theory of the multimodality of language to dwell upon the category of what he terms "storygames" (gropowieści), I believe a similar model can also be applied to other types of games. Even games that do not rely heavily on story (like sports games or puzzle games) still contain representational and aesthetic elements, as most cultural artefacts do.

Those four elements together, then - story, space, rules and gameplay - are crucial to understanding the game's message. Majkowski connects these four elements into two sets of pairs, representing different dimensions of the game's signification. Rules and gameplay together account for the regulative-agential dimension of the game, while space and story make up its aesthetic-narrative dimension. At the same time, rules and space together are the game's systemic aspect, while space and story constitute its sequential aspect.[38]

The second arrangement of paired sets is particularly relevant here. The game's sequential elements, story and gameplay, produce game narration, which includes all situations and events that are experienced by the player or the protagonist, even those which might not be part of a predesigned story. Meanwhile, the game's systemic elements, space and rules, are a frame that allows those narrative instances to happen.[39] Despite having completely different qualities, those elements are intertwined with each other, and this process creates tension, which sometimes resolves into ludonarrative dissonance.

Ludonarrative dissonance is a term introduced by Clint Hocking to describe the moment when the ludic elements of the game (such as its mechanics) convey a different message than its narrative layer. A notable example of this phenomenon is the Uncharted series (2007-2017), where the main character, Nathan Drake, expresses his distaste for violence while killing hundreds of enemies.[40] This seems to be a common problem for games with combat mechanics, where the protagonist is introduced in the story as a person who is not a killing machine (other examples include the new Tomb Raider series [2013-2018] or Red Dead Redemption [Rockstar San Diego, 2010]). Another very common form of ludonarrative dissonance is the verbal setting of time limits - or another form of temporal urgency - within the game's story, but which does not have a reflection in gameplay. This form of ludonarrative dissonance can often be found in open-world role-playing games, when the storyline of the main quest suggests urgency, but the player is free

[37] Por. T. Majkowski, Języki gropowieści: studia o różnojęzyczności gier cyfrowych, Kraków 2019, p. 120.
[38] Ibidem, p. 126.

[39] Ibidem, pp. 126-127.

[40] Ibidem, pp. 127-130. 
to explore other side-quests, wander randomly or play mini-games, pressing pause on what is happening in the main quest.

Clashes between layers of the digital game object that have different ontological qualities can also manifest in other ways. For example, glitches are a phenomenon that openly exposes the materiality of the game object to players, pushing them to think about its technological nature.[41] However, a number of designers have started to see that you cannot fully hide the materiality of the game object; that, on the contrary, it is an integral part of the play experience. This has led, in some cases, to the active foregrounding of the game's materiality as a part of the game's story line, or at least a part of the storyworld. It can be as simple as an Easter egg hidden somewhere in the game environment, or a rule that is fundamental for the whole game experience.

Piotr Kubiński has interpreted this phenomenon from the perspective of poetics. Emersion - as he calls it - is a mechanism, incidental or designed, that uncovers the fact that actions in which the player takes part have a mediated character. For him, actively designing for emersion is based on the need of artistic expression, defying the overuse of immersion as a goal in game design. [42] Games like The Stanley Parable (Galactic Café, 2011) or Deadpool (High Moon Studios, 2013), which break the illusion of the fourth wall, play with the player's conviction about the necessity of immersion, as well as their knowledge about the basics of game design. However, in titles such as Undertale or Doki Doki Literature Club (Team Salvato, 2017), the internal play with the game's digital materiality is not only the result of artistic expression, but is strongly rooted in the knowledge of how the game works and what the experience is built on. The designers of these games do not only play with the knowledge of how the game communicates with the player, but also with how the layer of fiction emerges from the digital materiality of the game object. In the next section, I will show how this type of design works in practice, focusing on the example of Undertale.

Undertale, created by Toby Fox, is an interesting combination of role-playing game with elements of bullet-hell game. Visually, the game makes use of very simple $2 \mathrm{D}$ pixel graphics with a limited colour palette; nonetheless, it conveys a coherent world inhabited by well-defined characters. The story of Undertale at first seems quite straightforward. The player-character, a human child named Frisk, wakes up in an underground land, and tries to find his way back up to the surface. From the very beginning, however, the player is tricked by their pre-existing knowledge of the JRPG genre. As you wake up surrounded by ruins inhabited by monstrous creatures, you are prone to think that you should defeat them all, especially given that Flowey, one of the first NPCs you encounter in the game, suggests as much.

The materiality of the Undertale world 
The user interface that appears during combat encounters indicates this as well, with the button "fight" ready to be pressed as one of the main actions that the player can take. However, after closer inspection, the player learns they can also have different interaction with enemies, which are hidden under the button "act". These interactions are much more peaceful; for example, you can talk, dance, flirt, wiggle with or pet your enemy, even if the enemy might continue to act aggressively and damage the player-character while you do so. However, after you form a proper connection with them, you can show mercy (another button on the interface) and spare them. This is the first moment when the player is forced to think deeper about the non-diegetic layers of the game in order to understand the story of Undertale, and what this unexpected twist to the generic expectations of how the game should play might mean.

In this case, the user interface (UI) is a constant reminder of the mediated status of the game experience, and the presence of the digital body of the game. Later in the game, it even becomes a part of the diegetic world. This happens during the game's boss encounters, most notably, the deadly duel with Asgore, in which he interferes with the UI and destroys the "mercy" button in the beginning of the confrontation, pushing players to use force and not communicative actions.

Even more sudden change happens when facing Flowey in combat later in the game. During this fight, the rules of the game are completely changed, along with its pixelated aesthetics. The interface is completely deconstructed, and the only options that appear occasionally on the screen, in isolation, are "fight" and "act". Flowey's power over the UI is not the only ability that this character possesses. Just before the confrontation, he makes the game crash, forcing the player to reopen it once again; however, once they do so, they find that they cannot go back to the previous save. From this moment, the save and restart option is unavailable. Flowey also communicates this directly to the player. From the perspective of digital materiality, the game state is stored in fileo inside the game file directory, and it is this file that is controlled by the actions of Flowey, even if the player was using it through the whole game. [43]

This files manipulation serves the deeper meaning of the story of Undertale. Inside the game lore, the process of saving is explained as the creation of alternate timelines for the world of Undertale. What is interesting is that a few characters - like Sans and Flowey - recognize the fact that the player-character might have met them before. They can even judge you for your previous choices, even after having reloaded from an earlier save. The game also remembers the name you chose in the first run of the game.

[43] More information about the save mechanism in Undertale can be found here: <https://undertale. fandom.com/wiki/SAVE $>$, accessed: 21.01.2021. 
This mechanism also influences the ending of the game. There are three main endings to the game: Neutral Ending, Pacifist Ending and Genocide Ending (no mercy). The Neutral ending allows the player to play the game once again, to experience the true positive ending. When the game is reloaded, some of the dialogues change, but we still can achieve two other endings (including the no mercy one). The situation is different for the Pacifist and Genocide endings. The Genocide ending is triggered by the player showing no mercy to any of the characters and enemies they meet, slowly becoming the villain of the story. After the final fight, we are informed by the mysterious and creepy Chara (who can be also interpreted as the evil reflection of the player's behaviour), that the only thing that is left to do is to "reset" this world, and go to the next one. If the player refuses, the game crashes on the desktop. The player can restart it, but they will be welcomed by ten minutes of a black screen and the sound of howling wind, after which the choice can be made again.

In this case, however, even if the player decides to take a pacifistic route, the true positive ending is unavailable to them. The ending sequences suggest that the player's character was replaced by the evil Chara. The memory of the previous choices is embedded in the game files, buried in its digital materiality - an instance of forensic materiality, to use Kirschenbaum's term. The Genocide ending is influenced in a similar way. The player can, of course, try to change the game files, but it is quite a complicated process, especially if the game was purchased and played via a digital distribution platform like Steam. For an ordinary player, this is not an easy operation; nonetheless, there are instructions in the Undertale fan community which explain step by step how to do it.[44]

The so-called "true reset" is possible only after we complete the Pacifist route, without having committed a Genocide run before. This reset choice is also difficult, because Flowey (as one of the most meta-conscious character) informs you that, if you do it, you will erase the happiness and completion that all the characters in the game have finally managed to achieve, restarting the circle of violence once again. What is interesting is that, even after the "true reset," while the character in the game does not have any recollection of the past events, we can still find a save file titled 'file8,' which is created after Flowey transforms from a small $2 \mathrm{D}$ character to a Photoshopped collage version of himself during the final fight. The memory of the player's previous actions are imprinted in the digital materiality of the game object.

There are even more secrets hidden inside the game files, influencing the whole mythology of Undertale. Another example is W.D. Gaster, a mysterious character who is only hinted at in the main story. Less observant or unlucky players might never see a trace of him. In

[44] More information can be found here: $<$ https:// www.gameskinny.com/fqmug/how-to-do-a-soft- and-hard-reset-after-an-undertale-genocide-run>, accessed: 21.01.2021. 
person, he appears only in one room, and only when the fun value[45] of the game is set to the specific number of 66 . Sometimes, when the fun value has the required number, you can meet other beings that mention him and hint at the secrets behind his character. There is also a hidden room that can be accessed only through manipulating save files or using the debug menu. In short, it is only through the manipulation of the game object materiality that the secret story of W.D. Gaster can unfold.

There are more pieces of narration hidden inside Undertale, but most of these require us to look at the storyworld as something that is localized only through the illusion of the representational element, as Kantor called it. The storyworld here is anchored to the digital materiality of the game. It is hard to understand what is happening in the game - accepting, for example, all the crashes that happen during the confrontation with Flowey - without accepting the presence of the body of the game. The game object here is no longer only a digital space that creates the storyworld. It becomes an active part of storyworld, almost as if the game becomes the final character player has to face. The game, then, is not only a digital partner we play with, but also a keeper of secrets. Therefore, some of the more inquisitive players turn to the game files to look for more clues that will help them uncover more truth about the world of Undertale. These players have even found a particular audio file (abc_123_a.ogg) left behind by Toby Fox, which contains a short message. The original message, voiced with text-to-speech synthesizers, asks curious players not to share the secrets they find with the online community, because that would spoil the fun. It also contains a threat that, if someone leaks secrets to the public, there would be no more new ones. Not surprisingly, the audio file was posted online by fans, and, in the later version of the game, was replaced by an eerie synthesized laugh.[46] This is another mischievous example that emphasizes the importance of the digital materiality of the game as something that allows playful actions, but also as being an important part of the storyworld experience. Following the premises of Leino's work about playable artifacta, we can read this as an example of how materiality and the process of play are intertwined with each other. Only in this way can the world of Undertale be filled with secrets.

\section{Conclusion}

Undertale is not the only game that plays with such metadesign techniques to create a new experience for the player. Other games, such as Doki Doki Literature Club (Team Salvato, 2017) or The Stanley Parable, also push their players to not only reflect upon the game's materiality, but also to tinker with it. Some of the secrets in The Stanley Parablelike the so-called "Serious Ending" - are hidden and only accessible

[45] The fun value is a mechanism that uses randomly generated number from 1 to 100 . Each number indicates which events, characters or lines of dialogue will be experienced by the player after they reset the game.
[46] You can read more about this and other files here: <https://undertale.fandom.com/wiki/Unused_ Music_Tracks>, accessed: 21.01.2021. 
through typing a specific command in the console menu. This tinkering is even more profound in Doki Doki Literature Club, where the player has to delete some of the game files to actually finish the game. What such playful gaming instances foreground is that the narrative layer is not the goal of the game software's existence; it is a ready-made part of it. It is revealed through the performative actions of the bodies of play; were it not for the interaction between the digital body of the game and the human body of the player, the fiction would never exist. As Kantor explained, "The FICTION (plot) of a drama, continuously disappearing and reappearing, "shone through" the "life" of these bio-objects. [...]." [47] The creative co-existence of those bodies and the performative nature of their bond allows the narrative layer of the game to appear. With every step and action inside the game that the player takes, there is a chance that a set of gameplay choices would resolve with a story waiting to be told. It does not have to be the big, epic story of a glorious hero. The story can be as small as a few second of gibberish dialogue that was forgotten by the designer and left inside the game files, only to abruptly appear and bring something new to the game experience. As the bodies inside Kantor's bio-object often behaved erratically during the performative action of the play, the fiction "suddenly disappeared inexplicably; at times, it appeared unexpectedly" [48], but it never vanished entirely, or lost its meaning. Therefore, fiction can neither appear outside the materiality of the game, nor can the materiality of the game object escape the fiction that tries to cover it. All of the bodies of play, human and non-human, are intertwined together to perform the meanings through their own materiality.

Aarseth E., Doors and perception: fiction vs. simulation in games, "Intermédialités / Intermediality" 2007, no. 9, p. 35-44, <https://doi.org/10.7202/1005528ar>, accessed: 21.01 .2021

Apperley T., Gaming Rhythms: Play and counterplay from the situated to the global, Amsterdam 2010

B.d., Interview with Yuk Hui in Popphilosophy, 24 February 2017, <http://philochina.org/?p=231>, accessed: 21.01.2021

Calleja G., In-Game: from immersion to incorporation, Cambridge 2011

Cyberpunk 2077 (CD Projekt, 2020)

Firewatch (Campo Santo, 2016)

Fortnite: Battle Royale (Epic Games, 2017)

Galloway A.R., Gaming: Essays on algorithmic culture, Minneapolis 2006

Hui Y., Towards a relational materialism, "Digital Culture \& Society" 2015, vol. 1, no. 1

Hui Y., What is a digital object?, "Metaphilosophy" 2012, vol. 4, no. 43

Janik J., Ghosts of the present past: Spectrality in the video game object, "Journal of the Philosophy of Games” 2019, vol. 1, no. 2, <https://journals.uio.no/JPG/ article/view/2943>, accessed: 21.01.2021

[47] T. Kantor, The Room..., p. 359.

[48] Ibidem. 
Janik J., Glitched perception: beyond the transparency and visibility of the video game object, "TransMissions: Journal of film and media studies" 2017, vol. 2, no. 2, $<$ http://transmissions.edu.pl/glitched-perception-beyond-the-transparency-and-visibility-of-the-video-game-object/>, accessed: 21.01.2021

Juul J., The game, the player, the world: Looking for a heart of gameness, [in:] Level Up: Digital Games Research Conference Proceedings, ed. M. Copier, J. Raessens, Utrecht 2003, pp. 30-45

Kantor T., Teatr śmierci: Teksty z lat 1975-1984, Wrocław 2004

Kantor T., The Room: Maybe a New Phase (1980), [in:] M. Kobialka, Further On, Nothing: Tadeusz Kantor's theatre, Minneapolis 2009

Karhulahti V.-M., Defining the videogame, "Game Studies. the international journal of computer game research" 2015, vol. 2, no. 15, <http://gamestudies.org/1502/ articles/karhulahti $>$, accessed: 21.01.2021

Kirschenbaum M.G., Mechanisms: New media and the forensic imagination, Cambridge, MA, - London 2012

Klevjer R., Enter the Avatar. The phenomenology of prosthetic telepresence in computer games, [in:] The Philosophy of Computer Games, ed. J.R. Sageng, F. Hallvard, L.M. Tarjei, Dordrecht 2012

Kłossowicz J., Tadeusz Kantor - teatr, Warszawa 1991

Kubiński P., Gry wideo: Zarys poetyki, Kraków 2016

Leino O.T., Death loop as a feature, "Game Studies: the international journal of computer game research" 2012, vol. 12, no. 2, <http://gamestudies.org/1202/ articles/death_loop_as_a_feature>, accessed: 21.01 .2021

Maj K.M., Światotwórstwo w fantastyce. Od przedstawienia do zamieszkiwania, Kraków 2019

Majkowski T., Języki gropowieści: studia o różnojęzyczności gier cyfrowych, Kraków 2019

Malaby T., Beyond play: A new approach to games, "Games \& Culture" 2007, vol. 1 , no. 2

Pleśniarowicz K., Teatr Śmierci Tadeusza Kantora, Chotomów 1990

Rez (United Game Artists, 2001)

Robson J., Meskin A., Video games as self-involving interactive fictions, "The Journal of Aesthetics and Art Criticism" 2016, vol. 74, pp. 165-177, <https://doi. org/10.1111/jaac.12269>, accessed: 21.01.2021

Ryan M-L., Avatars of Story, Minneapolis 2006

Salen K., Zimmerman E., Rules of Play. Game design fundamentals, Cambridge 2004

Święcicki K., Historia w teatrze Tadeusza Kantora, Poznań 2007

Tetris Effect (Monstars Inc. \& Resonair, 2018)

Van de Mosselaer N., Fictionally flipping tetrominoes? Defining the fictionality of a videogame player's actions, "Journal of the Philosophy of Games" 2018, vol. 1, no. $1,<$ https://doi.org/10.5617/jpg.6035> 